\title{
Spontaneous Blink Rates in Children During Different Types of Eye Movements
}

\author{
Michael S. Salman, Liumei Liu
}

\begin{abstract}
Introduction: The spontaneous blink rate (SBR) is variable in humans. It increases rapidly during childhood before reaching a plateau in adulthood at 10-20 blinks/minute. Our aim was to compare the SBR during different visual tasks in children. Methods: Thirty-nine healthy participants (mean age(SD):13.6(3.5)years, $\mathrm{M}=21$ ), made horizontal and vertical visually-guided saccades, tracked a horizontal and vertical target, performed horizontal and vertical active sinusoidal head rotations in light and darkness while looking straight ahead (VOR task) or fixated straight ahead and in four directions of gaze. The eyes of each participant were videotaped and reviewed twice to determine the SBR. Parametric and non-parametric tests were used to analyze the data. Results: The median SBR during fixation straight ahead was seven blinks/minute, which was similar to the SBR during horizontal saccades and horizontal smooth pursuit tasks. The median SBR during vertical smooth pursuit and vertical saccades were significantly lower than during fixation $(\mathrm{p} \leq 0.042)$. The median SBR during the VOR task in light and horizontal VOR in darkness were significantly higher than during fixation ( $\mathrm{p}=0.019-0.024)$. Conclusions: The median SBR during visual fixation was lower than that reported previously in 5-14 years-old children during rest or 11-20 years-old subjects during quiet conversation. The median SBR was even lower during vertical smooth pursuit and saccades tasks. This may be due to differences in concentration required for visual fixation in general and vertical visual tasks more specifically. The higher SBR during the VOR may be due to drying of the eyes during head shaking.
\end{abstract}

RÉSUMÉ: Fréquence du clignement spontané des yeux chez les enfants pendant différents types de mouvements oculaires. Contexte : La fréquence du clignement spontané des yeux (FCS) est variable chez l'humain. Elle augmente rapidement pendant l'enfance et elle atteint un plateau à l'âge adulte à environ 10 à 20 clignements par minute. Le but de notre étude était de comparer la FCS pendant l'exécution de différentes tâches visuelles chez des enfants. Méthode : Trente-neuf enfants en bonne santé, dont l'âge moyen était de 13,6 ans (ÉT de 3,5 ans) et dont 21 étaient des garçons, ont participé à une étude comportant des saccades horizontales et verticales visuo-guidées, la poursuite d'une cible horizontalement et verticalement, des rotations sinusoïdales actives de la tête dans le plan horizontal et vertical à la lumière et dans l'obscurité tout en regardant droit devant (tâche VOR) ou en fixant un point droit devant ainsi qu'en regardant dans les quatre directions. Les yeux de chaque participant ont été enregistrés sur bande vidéo au cours des tests et revus à deux reprises pour déterminer la FCS. Des tests paramétriques et non paramétriques ont été utilisés pour analyser les données. Résultats : La FCS médiane pendant que les sujets fixaient un point droit devant eux était de 7 clignements par minute, ce qui est similaire à la FCS pendant les saccades horizontales et la poursuite horizontale lente. La FDS médiane pendant la poursuite verticale lente et les saccades verticales était significativement moindre que pendant l'épreuve de fixation ( $\mathrm{p} \leq 0,042)$. La FCS médiane pendant le VOR dans une pièce éclairée et le VOR horizontal dans l'obscurité étaient significativement plus élevée que pendant la fixation ( $p=0,019$ et $\mathrm{p}=0,024$ respectivement). Conclusions : La FCS médiane pendant la fixation visuelle était inférieure à celle rapportée antérieurement chez les enfants de 5 à 14 ans au repos ou chez les sujets de 11 à 20 ans pendant une conversation tranquille. La FCS médiane était encore moindre pendant la poursuite verticale lente et les tâches de saccades. Ceci pourrait être dû à des différences dans la concentration requise pour la fixation visuelle en général et plus spécifiquement dans les tâches visuelles verticales. La FCS plus élevée pendant le VOR pourrait être due à l'assèchement des yeux lorsque le sujet secoue la tête.

Can J Neurol Sci. 2013; 40: 717-721

Blinks are fast eyelid movements that close and open the palpebral fissures. They are produced by antagonistic interaction between the levator palpebrae superioris muscle innervated by the oculomotor nerve and the orbicularis oculi muscle innervated by the facial nerve. ${ }^{1}$ During eyelid opening, both muscles exhibit a balanced level of tonic activity. The levator palpebrae superioris is inhibited during the closing phase and then the orbicularis oculi muscle contracts. Once the closing phase stops, the orbicularis oculi muscle resumes its tonic activity and levator palpebrae superioris contracts, raising the lid. ${ }^{1}$

There are three types of blinks: Spontaneous, reflexive and voluntary. The first two are involuntary to the subject's will, while the last one is volitional., ${ }^{2,3}$ Spontaneous blinking is an unconscious action that occurs without any evident stimulus while reflexive blinking occurs in response to visual, auditory, and somatosensory stimuli. Spontaneous blinking is essential for

From the Children's Hospital (MSS), University of Manitoba (LL, MSS), Winnipeg, Manitoba, Canada.

Received January 14, 2013. Final Revisions Submitted April 30, 2013. Correspondence to: Michael S Salman, AE308, Children's Hospital, 820 Sherbrook Street, Winnipeg, Manitoba, R3A 1R9, Canada. Email: msalman@hsc.mb.ca. 
the clarity of vision and ocular surface integrity. It distributes the tear film over the ocular surface and removes irritants from the surface of cornea and conjunctiva. ${ }^{2}$ The spontaneous blink rate (SBR) may vary with age, gender, and presence of specific neurologic (e.g. Bell's palsy, oculomotor palsy, Parkinson's disease, and myasthenia gravis) and psychiatric diseases (e.g. anxiety and schizophrenia), cognitive processes, attention level, and emotional state. ${ }^{1-5}$

Spontaneous blinking momentarily interrupts the visual input to the brain several times per minute. To overcome the blackout periods that occurs during blinking, visual sensitivity is reduced. This phenomenon is known as blink suppression. ${ }^{3}$

A wide variability of SBR in normal subjects has been reported in different age groups. ${ }^{6}$ However, the general trend of the SBR is that the rate is low during the fetal period and increases exponentially until it plateaus in adulthood with a mean rate of 10 to 20 blinks $/ \mathrm{min}^{3}$ A mean (SD) SBR of 0.7 (1.16) blinks/minute was reported during quiet wakefulness in 14 infants up to two months of age, ${ }^{7}$ and 14.3 blinks/minute in 200 preschool, four to six years old children. ${ }^{8}$ There is a paucity of studies on the SBR in older children and teenagers. ${ }^{3,7}$

In a series of studies on several types of eye movements in healthy children and adolescents, ${ }^{9-12}$ the first author noted that the participants did not blink much during the tasks. To investigate this observation further, videotapes of the participants' eyes during the tasks were analyzed for the SBR in this investigation.

The objectives of the study were to quantify the SBR during visual fixation and compare it across different types of eye movements in healthy school aged children and teenagers. We hypothesized that: 1) The SBR in the participants will be more than that in infancy and less than that in adulthood because blink rate increases with age, 2) the SBR will be lower during visuallyguided saccades to relatively small amplitude target steps and during smooth ocular pursuit than during visual fixation because these tasks demand more concentration, which is associated with lower blink rate, ${ }^{4,13}$ and 3) the SBR during the vestibulo-ocular reflex (VOR) task will be higher than during visual fixation because head shaking will dry the eyes, which is associated with a higher blink rate. ${ }^{3}$

\section{Methods}

\section{Participants}

A total of 39 well and healthy participants with a mean age (SD, age range) of $13.6(3.5,8-19)$ years were evaluated. Twenty-one were males. Visual acuity was at least $20 / 40$ in all participants. None wore contact lens or eyeglasses during the tasks. Participants with any disorder that may affect the blink rate or eye movements were excluded from the study. Guardian consent and the participants consent or assent was obtained. Ethical approval for the eye movements study was obtained from the local Research Ethics Board.

The visual tasks were performed during working weekdays throughout the summer holidays. In 32 participants, they were performed in the morning. The rest were performed in the early afternoon.

\section{Equipment and tasks}

All eye movement tasks were performed in a dimly lit room or in the dark at a constant temperature of $21^{\circ} \mathrm{C}$. During the tasks, participants sat on a chair facing a $45 \mathrm{~cm}$ computer monitor, $57 \mathrm{~cm}$ in front of their eyes. Their heads were positioned on a chin rest for all the eye movement tasks except for the VOR task. The visual stimulus displayed on the screen was a $2 \mathrm{~mm}$ white square light that subtended 12 minutes of arc at their cornea. The participants' eyes were videotaped using infrared cameras mounted on an eye tracker spectacle frame (ElMar Inc., Downsview, ON, Canada), which they wore while performing five distinct tasks in the following sequence: Visually-guided saccades, smooth ocular pursuit, fixation straight ahead, fixation in four directions of gaze, and the VOR. The image was sampled at $120 \mathrm{~Hz}$. For each task, a black patch was placed on the front of the eye tracker spectacle frame, 1-2 $\mathrm{cm}$ in front of the non-preferred eye (and the infrared camera), to ensure consistent viewing conditions throughout the tasks by the preferred eye only. Both eyes, however, were videotaped. Participants closed their eyes for 0.5-3 minutes to rest them between the tasks. They were actively encouraged to concentrate as they performed each task.

The saccade task consisted of 80 horizontal, followed by 80 vertical, visual target steps. The target stepped in an alternative manner between the central fixation point at the centre of the computer monitor and one of four eccentric locations before stepping back to the center of the computer monitor. The horizontal target locations were $10^{\circ}$ and $15^{\circ}$ to the right and left of the central fixation point, while the vertical target locations were $5^{\circ}$ and $10^{\circ}$ above and below the central fixation point. The number of target steps was 20 per amplitude per direction. The off-centre locations and timing of the target steps were unpredictable, with the latter ranging between one to one and a half seconds (s). The participants were instructed to look at the target. The duration of the saccade task was $102 \mathrm{~s}$ for each of the horizontal and vertical tasks.

The smooth ocular pursuit task consisted of following a visual target moving horizontally in a sinusoidal and smooth fashion on the computer screen. Twenty cycles between $-10^{\circ}$ and $10^{\circ}$ target amplitudes and $15.5^{\circ} \mathrm{s}$ peak target velocity were presented after an initial fixation period of $2 \mathrm{~s}$ followed by another 20 cycles at the same amplitudes but at $31 \%$ s peak target velocity. The same paradigm was then repeated vertically. The duration of the smooth ocular pursuit task was $126 \mathrm{~s}$ for each of the horizontal and vertical tasks. Fixation was performed using two paradigms. In the first, participants were instructed to look straight ahead at the central fixation point for one minute. In the second, participants were instructed to look at the visual target as it stepped sequentially leftward, upward, downward, and rightward starting and ending at the central fixation point. In each eccentric target location, which was $17^{\circ}$ in amplitude, the target remained on for $10 \mathrm{~s}$. The duration of the paradigm was one minute.

Last, the VOR task was performed in the light and then in the dark with horizontal followed by vertical active sinusoidal head rotations, at 0.5 and $2 \mathrm{~Hz}$ frequencies in each direction. Twenty cycles at each frequency, direction, and condition (i.e. light and dark) were performed. The participants were instructed to look at the central fixation point during the VOR task in the light 
Table: Total, complete, and incomplete median (interquartile range, range) blink rates per minute during visual fixation

\begin{tabular}{lcc}
\hline & $\begin{array}{c}\text { On looking straight } \\
\text { ahead }\end{array}$ & $\begin{array}{c}\text { On looking in four } \\
\text { eccentric directions of gaze }\end{array}$ \\
\hline *Total blink rate: & $7(3.4-12.1,2-20.5)$ & $6.5(3-11,0.5-20)$ \\
Complete blink rate: & $4(2-9.1,0-13.5)$ & $3.5(1.5-8,0-15.5)$ \\
Incomplete blink rate: & $2(0.5-4.1,0-15.5)$ & $1.5(1-4,0-16.5)$ \\
\hline
\end{tabular}

* The total blink rate is not equal to the sum of complete and incomplete blink rates since the data distribution is skewed.

(visually-enhanced VOR task) and at the tip of their index finger of their outstretched right arm in the dark (VOR task in the dark). The duration of this task at the two frequencies was $50 \mathrm{~s}$ per direction for each of the light and dark conditions.

Participants were told that their eye movements were being monitored and recorded with no mention of blinks. Further details on each of the tasks is available elsewhere. . $^{9-12}$

\section{Analysis}

The second author reviewed the videotape of each participant's eyes in detail. Blinks were defined as complete when the upper eyelid margin touched the lower eyelid and incomplete blinks as any other movements of the eyelid in which the upper eyelid did not touch the lower eyelid. The number of complete and incomplete blinks per minute was counted for each task on two occasions separated by three weeks interval for each participant. The mean blink rate ascertained after the two videotape reviews was subsequently calculated for each task in each participant. Analyses were performed using a Statistical Package for Social Sciences version 19 (SPSS Inc., Chicago, IL, USA). Normality of the data was investigated using the mean, median, SD, skewness, kurtosis, box plots, and Shapiro-Wilk test. Mean and SD was used for normally distributed data and median with interquartile range and range for skewed data.

When the SBR distribution was skewed, logarithmic transformation of the data was undertaken in an attempt to normalize the data distribution. Normality of the resulting data distribution was investigated again. Parametric and nonparametric tests were subsequently used to compare the SBR during the various eye movement tasks. The SBR during fixation straight ahead was used as the baseline reference value. Significance was defined when $\mathrm{p}$ was less than 0.05 .

\section{Results}

Thirty five participants completed all the visual tasks with all 39 completing the saccade task and 38 completing the smooth pursuit and fixation straight ahead tasks. The mean number of saccades per target step and direction ranged between 12 and 18 . The mean number of smooth ocular pursuit cycles per peak velocity and direction ranged between 11 and 15 cycles. The mean number of VOR cycles per direction and condition (i.e. light and dark) was 11 for the $0.5 \mathrm{~Hz}$ and 26 for the $2 \mathrm{~Hz}$ head shaking frequencies. No correlation was found between the SBR and age or gender. The Table shows the SBR during visual fixation for complete, incomplete and total blinks. The total SBR was used for the rest of the analyses since each of the complete and incomplete median SBR was too small for further sub analyses. There was no statistical difference in the blink rates between participants who performed the tasks during the morning and those who performed the tasks during the afternoon.

The median SBR during vertical smooth pursuit (5.1 blinks/minute) and vertical saccades (5.9 blinks/minute) were significantly lower than during visual fixation $(\mathrm{p}=0.026$ and $\mathrm{p}=0.042$ respectively). The median SBR during the VOR in light for both vertical ( 9 blinks/minute) and horizontal (9.3 blinks/minute) directions and in the dark for the horizontal VOR (9.6 blinks/minute) were significantly higher than during visual

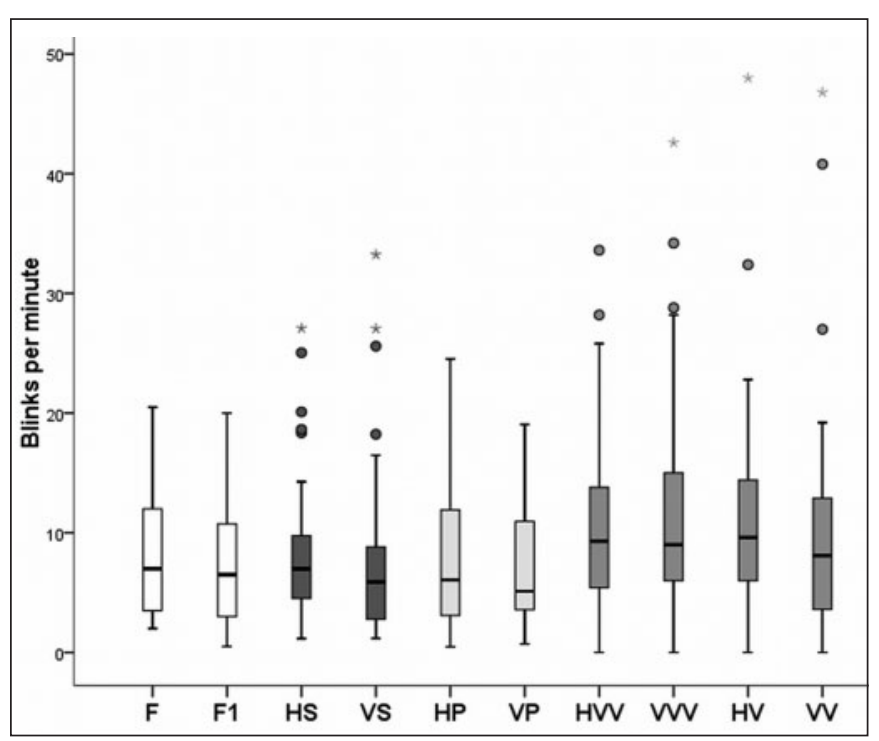

Figure: Standard box plots with median, interquartile range, and extreme values of the spontaneous blink rates during visual fixation straight ahead $(F)$, fixation in four directions of gaze (F1), horizontal $(H S)$ and vertical (VS) saccades, horizontal (HP) and vertical (VP) smooth ocular pursuit, visually-enhanced horizontal $(H V V)$ and vertical $(V V V)$ VOR, and horizontal (HV) and vertical (VV) VOR in the dark. 
fixation ( $\mathrm{p}=0.023, \mathrm{p}=0.024$, and $\mathrm{p}=0.019$ respectively). The $\mathrm{SBR}$ during the vertical VOR in the dark was also higher (8.1 blinks/minute) than during visual fixation but the difference was not significant $(\mathrm{p}=0.92)$. The SBR during horizontal saccades and horizontal smooth ocular pursuit were similar to the SBR during visual fixation. The Figure shows the SBR across the various eye movement tasks.

\section{Discussion}

Little research has been performed on the SBR in healthy school aged children and teenagers. The SBR has been reported to increase exponentially during childhood until it reaches mean adulthood values of 10-20 blinks/minute., ${ }^{3,7}$ However, Bentivoglio et al reported no correlation between the SBR (mean $=17$ blinks $/$ minute) and age in their 5-87 years old participants. ${ }^{4}$ Our study also revealed no correlation between the SBR and age. Preschool children aged four to six years made a total of 14.3 blinks/minute (complete blink rate of 8 and incomplete blink rate of 6.3 blinks/minute) while observing a target one meter away. ${ }^{8}$ In a study of children aged 5-14 years, the SBR during rest with the eyes open was about 19 blinks/minute, ${ }^{4}$ while another study reported a mean (SD) SBR during quiet conversation of 6.1 (3.2) blinks/minute in 96, 5-10 year old children, 10.3 (6.2) in 78, 1115 years-old, and 11.3 (6.7) in 23, 15-20 years old adolescents. ${ }^{7}$ These blink rates are generally higher than our findings in school aged children and teenagers during visual fixation, saccade and smooth pursuit tasks. The difference may be due to the concentration level required for the visual tasks in our investigation, where sustained visual attention was actively encouraged; and also the higher SBR reported during conversation, ${ }^{6}$ which was not investigated in our study. Visual tracking was associated with lower SBR in young infants. ${ }^{13}$ In addition, the SBR is reported to be lower when subjects perform tasks that require a high level of concentration such as reading, viewing a text on a video display, or watching a video game..$^{3-5,14}$

The SBR during visual fixation ranged from 0.5 to 20 blinks per minute, which is about one-half of the range found in the study of Abdulmnem et al, who reported a mean SBR of 26.1 and a large SD of 9.55 during conversation in their 91, 19-25 years old participants. ${ }^{6}$ However, the mean SBR (SD) was slightly lower in a subsample of their participants during class examination $[\mathrm{N}=19$, mean SBR $11.4(5)]$ or during a class lecture $[\mathrm{N}=19$, mean SBR16.4 (6.3)], likely because the cognitive demands are higher during these conditions. ${ }^{6}$ Several other studies have also reported on the large variability in SBR among their participants. ${ }^{3-5,7,14}$ A smaller variation in the SBR may be related to being engaged in the performance of visual tasks. ${ }^{4}$

The SBR during vertical smooth ocular pursuit and vertical saccade tasks were lower than during fixation. We propose that visual tasks involving vertical tracking may demand an even higher level of sustained visual attention than that required during visual fixation, horizontal saccades, and horizontal smooth ocular pursuit. This observation needs to be confirmed in future studies.

Blinks are more likely to accompany large amplitude saccades or gaze saccades (e.g. $33^{\circ}$ or more) than smaller amplitude saccades (e.g. $\left.15^{\circ}\right) .{ }^{15,16}$ Only small amplitude saccades were used in our investigation and thus the SBR was not expected to increase during the saccade task in our participants.
The higher median SBR during the VOR task in comparison with visual fixation may be due to several reasons. Drying of the eyes may occur during head shaking and dry eyes are associated with higher SBR. ${ }^{3}$ Blink frequency increases as a function of time on the task. ${ }^{17}$ This may be caused by the inability to inhibit blinking and may be the reason for the association between the higher SBR and fatigue. ${ }^{17}$ Therefore, fatigue may be another explanation for the higher SBR during the VOR task since it was the last task performed in our study. Blinks usually accompany gaze saccades during natural active head movements. ${ }^{18}$ Therefore; the VOR task would be anticipated to generate a higher frequency of blinks in comparison to visual fixation. However, such an explanation would predict many more blinks than that found in our investigation since participants made a mean of 11 head rotation cycles at $0.5 \mathrm{~Hz}$ and 26 head rotation cycles at $2 \mathrm{~Hz}$, but their median SBR was only between 9 to 10 blinks/minute during the VOR task. The infrared radiation from the eye tracker cameras at the eyes is relatively small (less than 0.5 milliwatt $/ \mathrm{cm}^{2}$ ). It is several orders of magnitude less than the radiation at the eyes on a bright day. Nevertheless, any radiation at the surface of the cornea may create a feeling of dryness that could potentially affect the blink rate, causing the higher SBR observed during the VOR task. This is unlikely however, since the SBR in our study tended to be generally low in comparison to other studies as mentioned above.

Our study limitations include the relatively small sample size and the short duration of each task. The latter was however necessary, since ocular motor experiments can be challenging to perform in children as they demand a lot of cooperation and concentration and are thus more time limited. The correlation between SBR and age can be investigated better using a longitudinal study design. Complete and incomplete blink rates were too small to analyze separately in this investigation. Their variations with different types of eye movements deserve further investigation.

\section{Conclusions}

The SBR during visual fixation is seven blinks/minute during late childhood and adolescence. The SBR varies during different types or directions of eye movements in school aged children.

\section{ACKNOWLEDGEMENT}

The authors thank The Manitoba Institute of Child Health for infrastructure support and summer studentship award. 


\section{REFERENCES}

1. Karson CN. Blinking. Bull Soc Belge Ophtalmol. 1989;237: 443-57.

2. Bacher LF, Smotherman WP. Spontaneous eye blinking in human infants: a review. Dev Psychobiol. 2004;44(2):95-102.

3. Cruz AA, Garcia DM, Pinto CT, Cechetti SP. Spontaneous eyeblink activity. Ocul Surf. 2011;9(1):29-41.

4. Bentivoglio AR, Bressman SB, Cassetta E, Carretta D, Tonali P, Albanese A. Analysis of blink rate patterns in normal subjects. Mov Disord. 1997;12(6):1028-34.

5. Cardona G, García C, Serés C, Vilaseca M, Gispets J. Blink rate, blink amplitude, and tear film integrity during dynamic visual display terminal tasks. Curr Eye Res. 2011;36(3):190-7.

6. Abdulmunem M, Briggs ST. Spontaneous blink rate of a normal population sample. ICLC 1999;26:29-32.

7. Zametkin AJ, Stevens JR, Pittman R. Ontogeny of spontaneous blinking and of habituation of the blink reflex. Ann Neurol. 1979;5(5):453-7.

8. Lavezzo MM, Schellini SA, Padovani CR, Hirai FE. Eye blink in newborn and preschool-age children. Acta Ophthalmol. 2008;86 (3):275-8.

9. Salman MS, Sharpe JA, Eizenman M, et al. Saccades in children. Vision Res. 2006;46(8-9):1432-9.

10. Salman MS, Sharpe JA, Lillakas L, Dennis M, Steinbach MJ. Smooth pursuit eye movements in children. Exp Brain Res. 2006;169(1):139-43.
11. Salman MS, Lillakas L, Dennis M, Steinbach MJ, Sharpe JA.The vestibulo-ocular reflex during active head motion in children and adolescents. Childs Nerv Syst. 2007;23:1269-74.

12. Salman MS, Sharpe JA, Lillakas L, Steinbach MJ. Square wave jerks in children and adolescents. Pediatr Neurol. 2008;38:16-9.

13. Bacher LF, Allen KJ. Sensitivity of the rate of spontaneous eye blinking to type of stimuli in young infants. Dev Psychobiol. 2009;51(2):186-97.

14. Himebaugh NL, Begley CG, Bradley A, Wilkinson JA. Blinking and tear break-up during four visual tasks. Optom Vis Sci. 2009; 86(2):E106-14.

15. Evinger C, Manning KA, Pellegrini JJ, Basso MA, Powers AS, Sibony PA. Not looking while leaping: the linkage of blinking and saccadic gaze shifts. Exp Brain Res. 1994;100(2):337-44.

16. Fogarty C, Stern JA. Eye movements and blinks: their relationship to higher cognitive processes. Int J Psychophysiol. 1989;8(1): 35-42.

17. Fukuda K, Stern JA, Brown TB, Russo MB. Cognition, blinks, eyemovements, and pupillary movements during performance of a running memory task. Aviat Space Environ Med. 2005;76(7 Suppl):C75-85.

18. Black RA, Halmagyi GM, Curthoys IS, Thurtell MJ, Brizuela AE. Unilateral vestibular deafferentation produces no long-term effects on human active eye-head coordination. Exp Brain Res. 1998;122(3):362-6. 